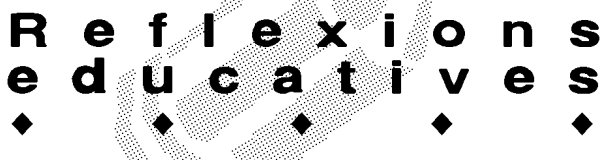

\section{LA NECESSITAT D'UN LABORATORI DE CIÈNCIES SOCIALS A L'ESCOLA I A L'INSTITUT}

\author{
Antoni Gavaldà Torrents i Antoni Santisteban Fernández. \\ Àrea de Didàctica de les Ciències Socials. URV.
}

Els centres escolars han de tenir els seus projectes de futur, que obrin nous camins de renovació, tant en el que fa referència a propostes de les diferents àrees curriculars com en el que pertoca a l'organització dels espais físics. De vegades, aquestes dues qüestions van unides, com en el cas de la nostra proposta: el "Laboratori de Ciències Socials". Som conscients de la necessitat d'un canvi en les classes dels estudis socials, i aquest espai podria ser un instrument important per aconseguirlo. Això podria implicar que les classes d'estudi de la història, de la geografia o de les ciències socials siguin alguna cosa més -quant a la seva naturalesa pràctica o procedimental- que llegir el llibre de text i subratllar-lo, pintar mapes, memoritzar algun resum que proposa el llibre de text...

Un nou espai físic no ha de significar per si mateix un canvi, però pot ser un bon instrument per a aquells centres o mestres que, cansats de reproduir un mateix model de classes, busquin solucions per renovar els seus ensenyaments socials. Tampoc la disponibilitat de nous materials curriculars no significa un canvi per si mateixos, però per a aquells que es troben en la recerca de la innovació és també un instruments molt útil.

\section{Què s'ha de fer des de la formació del professorat?}

Pensem que l'ensenyament i l'aprenentatge de les ciències socials s'ha de realitzar a partir de l'experimentació i el descobriment, la reconstrucció de les idees socials que ja tenen els alumnes a partir de recursos innovadors, el desenvolupament d'una actitud per a la investigació, la formació del pensament crític i creatiu, el debat i l'argumentació, la construcció de models i d'instruments...

Per aquest motiu, des de la universitat, aquest curs hem començat a treballar, de manera renovada, les pràctiques en la formació inicial del professorat, havent creat el nou laboratori de Didàctica de les Ciències Socials. Amb aquest projecte incipient volem aconseguir una meta que hem defensat a la universitat des de fa deu anys. Al llarg de tot aquest temps, com a preparació i justificació teòrica del nostre model, hem realitzat un ventall d'experiències i activitats pràctiques. Tot aquest material ens ha servit de base i de fonament per al disseny, organització i funcionament inicial del laboratori de Didàctica de les Ciències Socials. També hem aprofundit en els diferents aspectes 0 apartats que haurien de formar part d'unes pràctiques més participatives a la nostra assignatura. Veiem alguns d'aquests apartats treballats.

- Pràctiques relacionades amb la formació de l'opinió i l'emissió de judicis sobre qüestions socials, així com amb el debat i l'argumentació.

- L'anàlisi crítica de materials curriculars i l'elaboració de propostes didàctiques.

- Construcció de materials curriculars escrits, visuals i audiovisuals, jocs de grup i de simulació.

- Construcció de models, maquetes, esquemes, mapes conceptuals i semàntics, materials clàssics i utilització de les noves tecnologies de la imatge i de la informàtica.

- Creació d'arxius de tot tipus, com a materials de consulta per al professorat i com a propostes didàctiques d'utilització per a l'alumnat.

- Confecció d'un arxiu de materials descriptius i enregistraments de les classes de ciències socials.

- Materials de projectes d'investigació realitzats per l'alumnat de formació inicial del professorat.

Totes aquestes experiències s'han portat a terme en assignatures diverses, de vegades optatives o de lliure elecció: "Projectes d'investigació en Didàctica de les Ciències Socials" o "Les fonts històriques i l'ensenyament de la història". I, cada vegada més, ens hem convençut de la importància de disposar d'un laboratori específic de la nostra àrea de coneixement. Les raons d'aquesta necessitat són múltiples.

- El laboratori, com a espai físic, permet disposar de recursos didàctics de diversos formats, de fàcil organització i accessibles per a una utilització freqüent.

- Pot organitzar-se i disposar-se de manera ideal arxius d'història oral, de premsa, d'imatges, així com de tot tipus de fonts d'informació històrica, geogràfica, antropològica, artística, etc.

- Podem utilitzar tot tipus de materials o instruments 


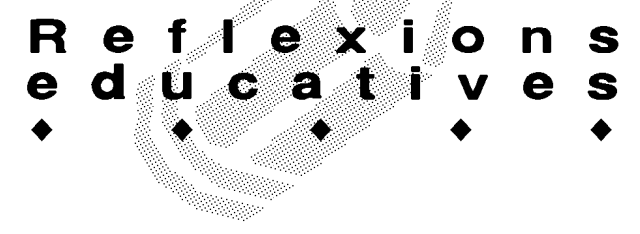

per a la creació de propostes, així com per a la construcció de maquetes o models geogràfics.

- Les noves tecnologies permeten disposar d'una informació que pot ajudar a donar un nou significat al que fem a les nostres classes, i el accés a la informació en xarxa ha de modificar també la nostra feina diària.

- L'espai ha de facilitar la realització de treballs cooperatius, el debat, la dramatització o l'experimentació de jocs de taula o de simulació.

- L'organització de l'espai pot permetre tenir diferents estructures de treball permanent, racons 0 tallers, que faciliten tasques distintes a diverses persones o grups.

- El laboratori, en similitud al d'altres disciplines amb més tradició pràctica, permet tenir preparades les pràctiques que s'han de realitzar i, a més a més, tenir preparades pràctiques distintes segons la persona o el grup, amb nivells de dificultat diferents.

- Finalment, el laboratori ha de ser també l'espai on s'ordenin, classifiquin i s'analitzin aquells enregistraments que mostren experiències, activitats o accions concretes recollides de les aules de ciències socials dels centres escolars.

Un dels apartats en què hem començat a treballar aquest primer curs és l'ordenació i classificació de materials, arxius i noves tecnologies, lectura i tractament de la imatge audiovisual i amb ordinador. També hem treballat en el disseny d'un model de fitxa per a cada una de les pràctiques que ha de realitzar el nostre alumnat (Quadre 1).

\section{Què proposem per a l'escola i a l'institut?}

El laboratori ha de significar un nou model d'intervenció didàctica, més democràtic, més participatiu, a favor d'un aprenentatge més autònom, on s'aprèn a través de les activitats pràctiques i del debat. Aquest plantejament és una obligació per a la universitat, però veiem que també ho ha de ser per a l'educació primària i secundària. Moltes de les qüestions que s'han plantejat anteriorment són aplicables o adaptables a qualsevol etapa de l'ensenyament.

Les possibilitats del laboratori són molt variades. A continuació repassarem alguns models o propostes que hem recollit i que estem experimentant nosaltres mateixos. Aquests projectes són realitats treballades al nostre país o a països de l'entorn. Per anomenar dos exemples, són conegudes les experiències angleses dels tallers d'història, com ara el projecte «Història 13-16», o les italianes sobre el tractament de les fonts històriques, especialment les fonts orals, el que alguns han denominat "laboratori de la memòria".

\section{Laboratori de la memòria}

Fa referència a l'arxiu de fonts històriques orals extretes dels mateixos familiars de l'alumnat, a partir d'entrevistes realitzades pel mateix alumnat als pares 0 als avis. L'estudiant fa la feina de l'historiador, recull les fonts, les analitza i les classifica. La riquesa d'aquest treball és indiscutible, ja que els nens i nenes o els nois i noies comproven la validesa de les fonts i la importància de la memòria individual, col-lectiva o històrica. Un treball constant també proporciona a l'escola un fons molt valuós de documents sobre la història de la vida quotidiana, esdeveniments polítics, etc.

\section{Taller de fonts primàries}

Les fonts primàries al laboratori poden ser diverses,com ara reproduccions en forma d'imatges fotocopiades, així com documents fotogràfics o escrits aportats pel mateix alumnat, que són arxivats per al seu tractament informàtic i la seva posterior observació o utilització: fonts materials, gràfico-documentals (públiques i privades), periodístiques, literàries, etc.

\begin{tabular}{|c|c|c|c|c|c|}
\hline \multicolumn{4}{|c|}{$\begin{array}{l}\text { URV. Didàctica de les Ciències Socials } \\
\text { Pràctiques }\end{array}$} & \multirow[t]{2}{*}{ Clau } & \multirow[t]{2}{*}{ Núm. } \\
\hline $\begin{array}{l}\text { Cicle } \\
\text { Educatiu }\end{array}$ & & & $\begin{array}{l}\text { Disciplina } \\
\text { social }\end{array}$ & & \\
\hline \multicolumn{6}{|l|}{$\begin{array}{l}\text { Nom de la } \\
\text { pràctica }\end{array}$} \\
\hline \multirow[t]{2}{*}{ Objectiu } & & & & & \\
\hline & \multicolumn{5}{|l|}{ F/C } \\
\hline \multicolumn{6}{|l|}{$\begin{array}{l}\text { Continguts } \\
\text { curriculars }\end{array}$} \\
\hline & \multicolumn{5}{|l|}{$A / N / V$} \\
\hline $\begin{array}{l}\text { Tipus de } \\
\text { treball }\end{array}$ & $\begin{array}{l}\text { Indivi- } \\
\text { dual }\end{array}$ & $\begin{array}{l}\text { Gru } \\
\text { p }\end{array}$ & $\begin{array}{l}\text { Grup } \\
\text { classe }\end{array}$ & Com & \\
\hline \multicolumn{6}{|l|}{$\begin{array}{l}\text { Procés de } \\
\text { treball }\end{array}$} \\
\hline \multicolumn{6}{|l|}{$\begin{array}{l}\text { Material } \\
\text { necessari }\end{array}$} \\
\hline $\begin{array}{l}\text { Avaluació } \\
\text { del propi } \\
\text { treball i de la } \\
\text { participació }\end{array}$ & & & & & \\
\hline
\end{tabular}

Quadre 1. Model de fitxa per a cada una de les pràctiques realitzades pels alumnes de l'Ensenyament de Mestres 


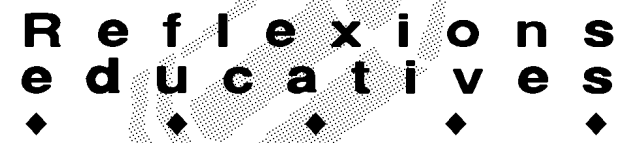

\section{Bases de dades}

Es tracta de crear una sèrie de bases de dades $i$ arxius per a la seva utilització a la classe de ciències socials, com per exemple un arxiu de notícies a partir de fitxes classificades i facilitar-ne el seu ús, un arxiu del patrimoni artístic de la zona, etc. Poden ser elaborats pel mateix alumnat, segons l'edat, fet que pot ajudar també a aprendre a organitzar una base de dades.

\section{Taller de lectura de la imatge}

En aquest apartat analitzaríem la composició i la interpretació de la imatge de publicitat, de la televisió, de la imatge històrica a l'art. També pot ser el camí per organitzar un taller de cinema com a recurs per al suport d'aprenentatges socials, ja siguin històrics o de valors.

\section{Informatica i Didàctica de les Ciències Socials}

L'ordinador permet la utilització d'internet com a font d'informació actualitzada i d'accés instantani. D'altra banda, molts materials curriculars, quan són informatitzats, es fan més accessibles i àgils en el seu ús, augmentant la rapidesa en la búsqueda de la informació.

\section{Laboratori per al joc i la simulació}

Es tracta de disposar d'una sèrie de jocs de grup i de jocs de rol per a l'estudi de diversos aspectes de la societat que requereixen el desenvolupament de capacitats per a l'empatia.

Altres materials curriculars diversos

En aquest apartat incloem materials de difícil classificació, però d'un gran potencial, com són les fonts musicals, materials per al treball plàstic a partir del dibuix, la construcció, etc., així com les maletes didàctiques per a l'aprenentatge de les ciències socials, entre les quals cal comptar amb les maletes d'arqueologia, les de construcció d'edificis, les d'aprenentatge de valors, etc.

\section{Laboratori de la comunicació}

Són materials pensats per treballar d'una manera específica les habilitats cognitivo-lingüístiques, materials per al debat, exemplificacions de prejudicis, estereotips socials, opinions i judicis raonats, exemples de l'estructura de la argumentació escrita i oral, etc., referits, òbviament, a l'especificitat de les ciències socials.

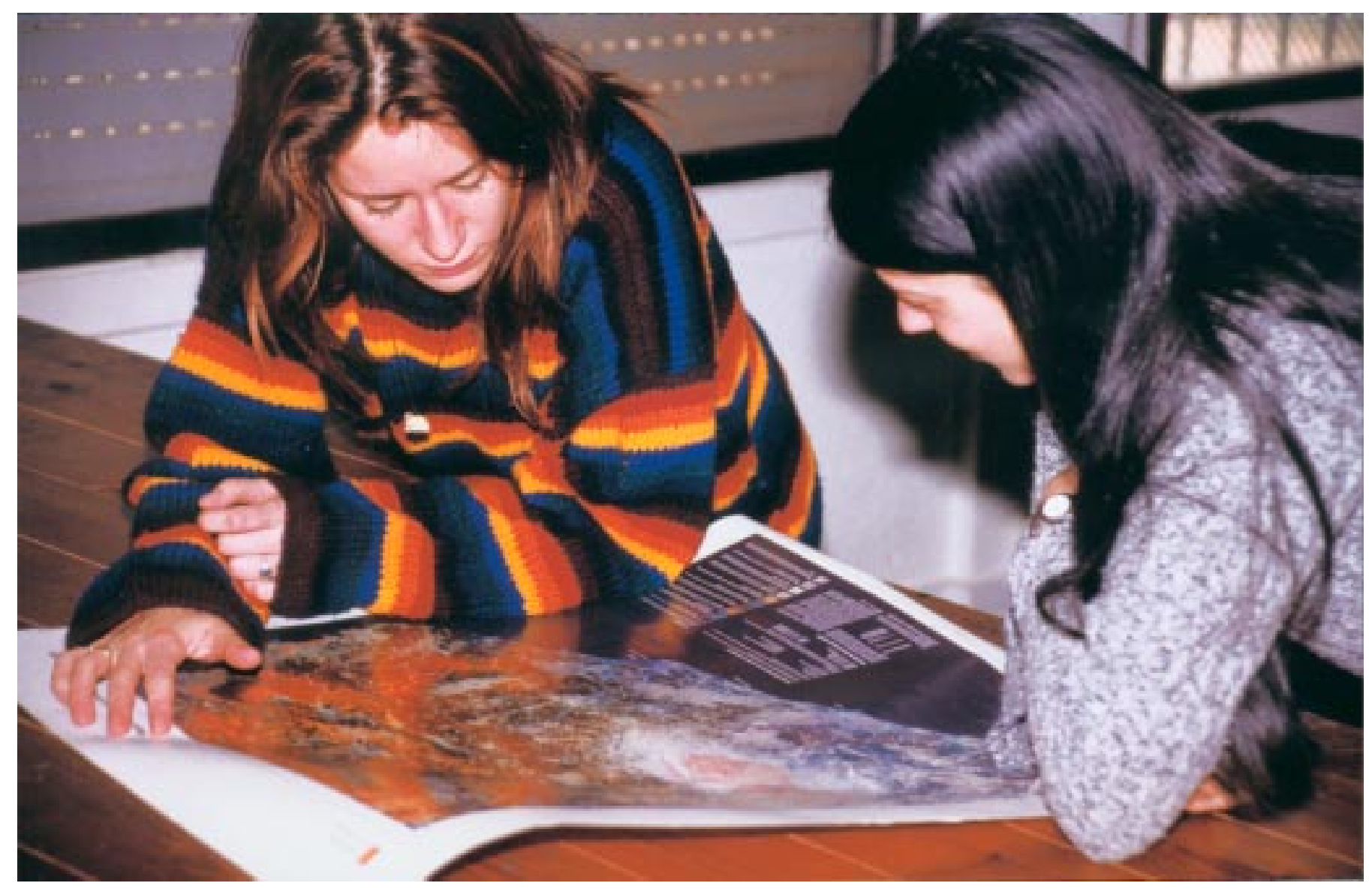

Alumnes de $3 r$ de magisteri trreballant al laboratori de Didàctica de les Ciències Socials 


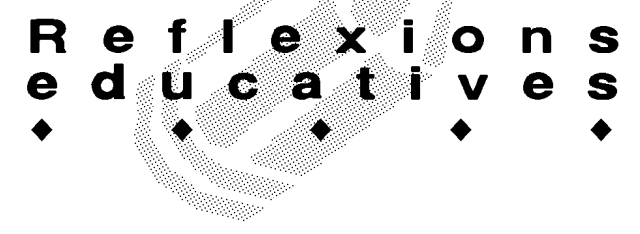

\section{Taller d'escriptors}

L'explicació històrica és la síntesi de la feina de l'historiador. El text de l'expert de qualsevol ciència social és l'últim pas de les seves investigacions. Per al nen o la nena, quan explica les seves idees sobre la societat es fa evident el seu autèntic coneixement. Quan les escriu està realitzant la part més dificultosa del seu aprenentatge. Per aquest motiu, des de la història personal fins a la sociologia del seu poble, l'ensenyament de les ciències socials ha de facilitar la maduració de l'alumnat com a observadors crítics de la societat, en el sentit de mesurar paraules en determinats contextos.

\section{Taller d'aprenentatge de l'espai geogràfic}

Per treballar la lateralitat, la situació a l'espai més quotidià o per treballar l'orientació, per a l'estudi dels mapes, per a la construcció de maquetes, per experimentar amb instruments de mesura, per analitzar fotografies aèries.

\section{Laboratori del temps històric}

Per treballar la complexitat d'aquest metaconcepte i per comprendre les possibilitats del seu ensenyament, des del vocabulari de les vivències més properes fins a la utilització de materials diferents de la cronologia o la periodització, com línies del temps, mesures diferents de les etapes històriques, etc.

\section{Tallers de ciències socials}

Es poden posar en pràctica diversos materials per treballar determinats continguts, com per exemple, de sociologia (les normes i la socialització), d'antropologia (la família), d'economia (el comerç i els bancs), de política (representativitat i poder), d'història de l'art (la composició visual i el context social).

\section{Laboratori del descobriment}

Es tracta de tenir exemples i models de treball per realitzar petites recerques en el medi social: enquestes, entrevistes, observacions, treballs de camp, etc.. Es tractaria d'educar una actitud oberta a la investigació. Amb enregistrament audiovisual podem fer molt més significatives les classes de ciències socials, i amb fitxes de recerca complementar buits que interessa anotar.

\section{Taller de la creativitat}

Es tracta de disposar de recursos i exemples per realitzar petits treballs per exposar. Un primer pas és desenvolupar capacitats per a l'elecció, bé sigui de fotografies, de diapositives o de seqüències filmades. També de textos o de fonts d'informació. Això implica tenir alguns instruments adequats, per exemple una taula de llum per a l'observació d'imatges de diapositives, auriculars, un ordinador per al tractament de la imatge, així com una biblioteca de consulta, etc. Un altre pas és la creació de materials, entre els quals comptem amb transparències, esquemes, fotografies o filmacions.

\section{Conclusions}

Pel que hem indicat, per a nosaltres el laboratori no és tan sols una estructura física o un conjunt de materials, sinó una organització de les pràctiques de les nostres classes amb una clara intencionalitat: formar el pensament, crític i creatiu, i fer més present la cultura democràtica a les nostres classes. Junts, professors i alumnes hem de trobar canals per a la renovació de l'ensenyament de les ciències socials. Hem d'aconseguir fer més funcionals les nostres classes i traspassar el debat a l'escola $i$ als instituts. Volem que la teoria i la pràctica siguin una unitat.

a) Volem, en primer lloc, que l'alumnat de qualsevol etapa educativa porti a terme la "pràctica de la racionalitat" aplicada a la comprensió del que succeeix al nostre voltant i a la resolució de problemes socials.

b) En segon terme, la "practica de la comunicació", amb alguns elements prioritzats com el debat, l'argumentació, la resolució de conflictes i la cooperació.

c) Tercer, la "pràctica de la creativitat", aplicada a la creació de materials per a l'estudi de la societat, representatius de les diferents disciplines socials.

d) Finalment, la "pràctica de la recerca", com la formació de persones que tinguin una actitud oberta a la investigació, oberts al coneixement intel.lectual i al saber construït des de paràmetres de raonament i de lògica científica.

El laboratori de Didàctica de les Ciències Socials es un camí que ens sembla interessant. Creiem que és un espai amb un gran significat per a la renovació de les classes de ciències socials i per a la innovació a totes les etapes educatives. 